\title{
Indicações Geográficas e Negociações Internacionais
}

\author{
Geographical Indications and International Negotiations
}

\author{
Alessandro Aveni ${ }^{1}$ \\ Carolina Leite Diniz Panzolini ${ }^{1}$ \\ Daniela Soares Couto Saldanha \\ Jéssica Pinto Lima ${ }^{1}$ \\ ${ }^{1}$ Universidade de Brasília, Brasília, DF, Brasil
}

\begin{abstract}
Resumo
Indicação Geográfica é a proteção dada a um território em razão da fama local atribuída a um determinado produto ou serviço. Os estudos que envolvem o tema são os mais diversos, entretanto, o presente artigo apresenta uma análise das indicações geográficas e sua correlação com negociações internacionais. Para tal, abordou-se a contextualização histórica, os entraves e os impactos econômicos das Indicações Geográficas, tudo em correlação com as negociações internacionais, comparando-se conceitos de Indicações Geográficas e suas ramificações, seus impactos em âmbito nacional e internacional. Considerando-se o sistema de políticas brasileiras relacionadas à propriedade intelectual e a Indicações Geográficas e entraves para as negociações internacionais, foi possível identificar, como resultado desta pesquisa, os pontos a serem explorados para garantir avanço e êxito nas tratativas internacionais.
\end{abstract}

Palavras-chave: Indicações Geográficas. Negociações Internacionais. Sistema Político.

\begin{abstract}
We have by Geographical Indications the protection given to the territory in function of the local fame attributed to a certain product or service. The studies that involve the theme are of the most diverse, however, the present article intends to present an analysis of the geographical indications and its correlation with international negotiations. The historical contextualization, the obstacles and the economic impacts of the Geographical Indications will be approached, all in correlation with the international negotiations. In the historical context it is significant to note that from a remote time it was usual to cite geographical names to identify products. The study compares concepts of Geographical Indications and their ramifications, their impacts at national and international level. As a result of the research, the study presents considerations under the Brazilian policy system related to intellectual property and Geographical Indications, and obstacles to international negotiations, where it is possible to identify the points to be explored to ensure progress and success in international negotiations.
\end{abstract}

Keywords: Geographical Indications. International Negotiations. Political system.

Área tecnológica: Propriedade Intelectual. 


\section{Introdução}

O escopo do conceito de Indicação Geográfica (IG) se bifurca em duas diretrizes: denominação de origem e indicação de procedência. Enquanto na denominação de origem a abrangência do conceito é maior e estabelece uma correlação dos produtos com a origem geográfica, considerando aspectos territoriais, naturais e humanos envolvidos na produção, na indicação de procedência, há uma interpretação mais restrita a partir do local e dos produtos ou serviços ali fornecidos, independentemente dos elementos geográficos associados ao produto.

Neste artigo, desenvolveu-se uma análise das IGs e sua correlação com as negociações internacionais mais relevantes. Para tanto, partiu-se de uma perspectiva histórica, contextualizada sob o marco legal referente às IGs, até um overview das atuais rodadas de negociações. Depois, foram identificados os principais entraves para o avanço das negociações internacionais relacionadas às IGs, no Brasil, além de observados os possíveis impactos econômicos nos segmentos dos produtos analisados e mencionadas eventuais solucões alternativas de ativos intelectuais similares às IGs. Por fim, foram analisadas as características dos sistemas políticos, especialmente do Brasil e da Europa, e seus impactos sobre as particularidades, o reconhecimento e as negociações das IGs.

Embora o Brasil tenha um grande potencial, sob o ponto de vista cultural, natural, geográfico, artístico, humano, entre tantos outros, não se avançou muito no âmbito das IGs. Atualmente, são pouco mais de 50 IGs reconhecidas no Brasil.

A definição de IG é uma denominação criada para se agregar valor a um produto a partir de características da sua origem, do seu modo de fazer, dos aspectos históricos e humanos envolvidos, de maneira a imprimir atributos individualizados para valorizar os produtos comercialmente.

O instituto da IG talvez seja a única área de conhecimento da Propriedade Intelectual que proteja o significado simbólico e comercial de um produto, a partir de um saber fazer, sob a perspectiva territorial, comunitária e associativa. Isso significa dizer que a proteção daquele produto não será conferida a uma pessoa física, mas a uma comunidade, normalmente constituída sob uma associação, de forma horizontal e linear.

\section{Metodologia}

Este artigo trata-se de uma pesquisa descritiva em que a participação em rodadas de negociação internacionais possibilitou a percepção, a identificação, o registro e a análise de diversos fatores que se relacionam com todo o processo de negociação internacinal, no que se refere às IGs. Segundo Perovano (2014), esse tipo de pesquisa pode ser entendida como um estudo de caso em que, depois da coleta de dados, realiza-se uma análise das relações entre as variáveis para uma posterior determinação dos efeitos resultantes em sistema, considerando-se uma série de elementos intrínsecos e extrínsecos ao processo, que envolvem desde técnicas e estratégias de negociações, diferenças culturais até o mérito técnico do debate.

A metodologia da pesquisa compreendeu a coleta de dados dos documentos disponíveis em sítios on-line e em documentos (em sua maioria sigilosos) apresentados durante as negociações internacionais. Com isso foram avaliados relatórios nacionais e internacionais que mostram 
comparações entre países em relação à propriedade intelectual e à IG, e ainda foi avaliado o contexto nacional e os problemas que o Brasil enfrenta com IG.

Quanto à abordagem, realizou-se uma pesquisa qualitativa, para compreensão das IGs em âmbito internacional, produzindo-se informações aprofundadas por meio da análise bibliográfica.

\section{Resultados e Discussão}

Antes de tudo, é importante destacar a dificuldade de reunir uma comunidade que seja responsável pela elaboração de um produto e detentora do saber fazer desse produto. Por conseguinte, há todo um desafio em agregar as pessoas, em identifcar uma liderança, em consolidar as informações, em transmitir as orientações necessárias quanto ao instituto da IG. Em paralelo, há o trâmite jurídico, referente à constituição da associação e a sua dificuldade administrativa, até a produção de uma regulação específica, a exemplo de alguns processos envolvendo queijos ${ }^{1}$ e pesquisas sobre esse produto ${ }^{2}$.

Alberto Francisco Ribeiro de Almeida, em sua obra Indicações de proveniência, denominações de origem e indicações geográficas, apresenta um marco legal histórico importante:

Os usos e os costumes da Grécia Antiga e de Roma espelhados no quotidiano da vida destes povos evidenciam uma multiplicidade e heterogeneidade de nomes geográficaos colocados em produtos. Na Grécia Antiga eram famosas as estatuetas da cidade de Tânagra, o bronze da cidade de Corinto, o mármore da região da Frígia, os mantos de Pelena, a excelência do mel do monte Himeto, os cavalos da região da Tessália, a púrpura da ilha de Cítera, os perfumes, os panos finos ou o pergaminho da cidade de Pérgamo, as lãs e tecidos da cidade de Mileto, os vinhos das ilhas de Tasos, de Quios, de Lesbos, de Naxos, de Lêucade, os da região da Calcídica, e da Trácia e os da cidade da Maroneia. Em Roma eram célebres os vinhos de Falerno, de Alba, do monte Mássico e de Sorrento, as ostras de Brindisi, os vasos de Bizâncio, o açafrão do monte Córico, o azeite de Venafro e o mármore de Carrara. A Bỉblia é pródiga na citação de nomes geográficos na identificação de produtos: os cedos do Líbano, o ouro de Parvaim, os cavalos provenientes do Egipto e de Qué, o vinho de Helvon e a lã de Sacar. (ALMEIDA, 1999).

No Brasil, as primeiras considerações acerca de IGs se deram por meio do Decreto n. 16.254, de 19 de dezembro de 1923, que criou a Diretoria Geral de Propriedade Industrial e disciplinou sobre o tema nos artigos a seguir:

Art. 80. Não podem gozar da proteção deste regulamento as marcas de indústria e de comércio que contiverem:

4. ${ }^{\circ}$ indicação de localidade ou estabelecimento que não seja da proveniência do produto ou artigo, quer a essa indicação esteja junto um nome suposto ou alheio, quer não;

$10 .^{\circ}$ nome de um lugar de fabricação para designar qualquer produto natural ou artificial fabricado em outro lugar ou proveniente de lugar diverso;

Art. 81. Entendem-se por indicação da proveniência dos produtos a designação do

\footnotetext{
${ }^{1}$ Disponível em: <http://www.gazetadopovo.com.br/bomgourmet/lei-producao-queijos-artesanais-parana/> e <https://www.milkpoint.com.br/noticias-e-mercado/giro-noticias/comissao-aprova-proposta-que-regulamenta-a-producao-e-o-comercio-de-queijo-artesanal-108117n.aspx>. Acessos em: 28 dez.. 2018.

${ }^{2}$ Disponível em: <http://www.ima.mg.gov.br/acontece-no-ima/2321-governo-de-minas-libera-recursos-para-a-pesquisa-na-area-de-queijos-artesanais>. Acesso em: 28 dez. 2018.
} 
nome geográfico que corresponde ao lugar da fabricação, elaboração ou extração dos mesmos produtos. O nome do lugar da produção pertence cumulativamente a todos os produtos nele estabelecidos (56).

Art. 82. Ninguém tem o direito de utilizar-se do nome de um lugar de fabricação para designar produto natural ou artificial fabricado ou proveniente de lugar diverso (57).

Art. 83. Não haverá falsidade de indicação de proveniência quando se tratar de denominação de um produto por meio de nome geográfico que, tendo-se tornado genérico, designar em linguagem comercial a natureza ou gênero do produto. Esta exceção não é aplicável aos produtos vinícolas (58).

Art. 117. Será punido com multa de $200 \$ 000$ a 2:000\$000, aquele que:

4. ${ }^{\circ}$ usar marca de indústria ou de comércio com indicação de localidade ou estabelecimento que não seja o da procedência do produto ou artigo, quer a essa indicação esteja junto um nome suposto ou alheio, quer não;

6. ${ }^{\circ}$ vender ou expuser à venda produto ou artigo revestido de marca com indicação de localidade ou estabelecimento que não seja o da procedência do produto ou artigo, quer a essa indicação esteja junto um nome suposto alheio, quer não (92). (BRASIL, 1923).

Em 1945 foi criado o primeiro Código de Propriedade Industrial, o qual, instituído pelo Decreto n. 7.903, de 4 de fevereiro de 2013, limitou o registro de marcas que representasse uma IG:

Art. 95. Não podem ser registradas como marca de indústria ou de comércio;

$7^{\circ}$ ) o nome ou indicação de pai região, localidade, ou estabelecimento de notório conhecimento como centro de fabricação ou extração dos produtos, esteja ou não junto a essa indicação um nome suposto ou alheio. (BRASIL, 2013b).

Com a publicação do Decreto-Lei n. 254, de 28 de fevereiro de 1967, foi promulgado um novo Código de Propriedade Industrial, contudo, este não apresentou novidades sobre IGS, mantendo-se as deliberações de 1945. O que também ocorreu com o Código de 1969, instituído pelo Decreto-Lei n. 1.005, de 21 de outubro de 1969.

Assim que a Lei n. 5.648, de 11 de dezembro de 1970, instituiu o Instituto Nacional de Propriedade Industrial (INPI), foi promulgado, por meio da Lei n. 5.772, de 21 de dezembro de 1971, um novo Código de Propriedade Industrial, o qual, a exemplo dos anteriores, não trouxe alterações relevantes sobre IGs.

Apenas com o atual Código de Propriedade Industrial - Lei n. 9.279, de 14 de maio de 1996 - é que as IGs alcançam proeminência, sendo alargada a tutela jurídica, e as definições de IGs em sua dupla modalidade são apresentadas: Indicação de Procedência e Denominação de Origem.

Embora haja legislação brasileira sobre IGs, resta a necessidade de normatização de algumas questões não alcançadas pela Lei n. 9.279/1996. Nesse sentido, o Acordo sobre Aspectos dos Direitos de Propriedade Intelectual Relacionados ao Comércio (TRIPS) - sigla em português - é o instrumento pelo qual, em 1994, a comunidade internacional recepcionou o instituto da IG, de modo que a novas regulamentações nacionais que se aproximem do instituído em âmbito internacional tendem a flexibilizar as negociações internacionais. 
As considerações sobre propriedade intelectual devem estar presentes desde as fases iniciais de cada projeto, com reflexos diretos na definição dos requisitos dos produtos a serem produzidos e no gerenciamento dos custos de produção e/ou de utilização. Segundo Amorim e Miskulin (2010), pesquisas recentes indicam que seis ações fundamentais são necessárias na maioria dos contextos: i) planejar a gestão da propriedade intelectual, ii) definir a política de propriedade intelectual, iii) identificar as autorizações necessárias, iv) adquirir as autorizações e/ou licenças de uso, v) coletar os termos de cessão dos recursos humanos envolvidos na produção e vi) arquivar a documentação.

\subsection{Perspectiva Nacional e Internacional}

Os tratados internacionais ocupam papel de destaque no que se refere ao comércio e ao intercâmbio econômico das IGs. Esses tratados possibilitam criar marcos legais internacionais para pacificar relações e entendimentos e fomentar parcerias comerciais entre países.

Com o ambiente digital, a internet, a globalização, entre outros fenômenos, a questão da territorialidade ganha contornos mais flexíveis e o tempo alçou um status incrivelmente veloz. Ademais, as trocas de informações e influências ficaram mais ricas e ativas, tornando o mundo atual um campo fértil para as negociações das IGs.

A União Europeia (EU) também vem se articulando com a China de forma incisiva, com o objetivo de viabilizar mais exportações àquele país. Recentemente, foi veiculado que a China recebeu $8,7 \%$ do total exportado, sendo considerada o segundo maior importador dos produtos da UE. A intenção, agora, é promover produtos com IGs, orgânicos e demais produtos de qualidade. Como parte da estratégia de estreitamento das relações e ampliação das parcerias comerciais, foi realizada a viagem de uma comitiva de empresários, juntamente com Phil Hogan (comissário de Agricultura da EU) em maio de 2018. Conforme publicado na revista Valor Econômico: "A UE destinou $€ 169$ milhões para promover seus produtos agrícolas no mundo este ano, $€ 27$ milhões a mais do que em 2017. De outubro de 2016 a outubro de 2017, as exportações do agronegócio europeu somaram € 137,4 bilhões." (MOREIRA, 2018).

O México também vem estabelendo tentativas de composição com a UE, por meio da busca de abertura de parcerias comerciais, de trocas de listas de IGs e de intercâmbio de oportunidades. Nesse sentido, no dia 21 de abril de 2018, a UE e o México celebraram um acordo político que irá abrir novos mercados para os produtores europeus. O movimento foi analisado sob uma perspectiva positiva pelo comissariado de Agricultura da EU, sendo considerado como uma ampliação de oportunidades e de aumento de exportação de produtos para o setor agrícola (VALERO, 2018). Não obstante, também há críticas ao avanço das tratativas e às condições impostas (U.S. DAIRY..., 2018).

O Reino Unido tem buscado alternativas de proteção de seus produtos e respectivas IGs, depois da consumação do Brexit, mas alega que está relutante em retribuir a essa proteção (STONE, 2018). Por outro lado, há países que estão se mobilizando para produzir regulamentos e assegurar a autenticidade de seus produtos, como é o caso da França com o queijo cabembert (LE FIGARO, 2018).

Atualmente, a negociação mais importante envolvendo o Brasil e o tema IGs é o capítulo de propriedade intelectual no acordo de comércio entre o MERCOSUL e a UE. O referido tema está sendo conduzido pelo Ministério das Relações Exteriores, com o apoio do Ministério do 
Desenvolvimento, Indústria e Comércio Exterior, além do Ministério da Agricultura. Entretanto, o Governo Federal se manifestou, por meio do então ministro da Agricultura, Pecuária e Abastecimento Blairo Maggi, que não acreditava em uma conclusão exitosa para o presente acordo (CHADE, 2018). Soma-se a essa declaração o fato de ser a IG um dos temas mais sensíveis (se não for o mais sensível) do capítulo da propriedade intelectual, em razão da sua complexidade técnica, geográfia, cultural, dos inúmeros impactos econômicos e da composição política, sempre necessária.

Segundo informações oficiais do Ministério do Desenvolvimento, Indústria e Comércio Exterior (BRASIL, 2017), como andamento das negociações, tanto o MERCOSUL quanto a UE trocaram listas com menção às IGs que pretendem reconhecer e proteger por meio do acordo. A UE indicou 347 IGs em sua lista; e o Mercosul, 200.

Como exemplos de IGs indicadas pela EU estão o "Presunto de Parma", o "Queijo de Gorgonzola", o "Espumante de Cava" e o "Presunto Toscano", além do "Queijo francês Gruyére" e dos italianos "Pecorino Romano" e "Parmigiano Reggiano" (este último, no Brasil, inclui o nome Parmesão). Entre as IGs do Brasil estão "Salinas" (para cachaça), "Serro" (para queijos) e "Vale dos Vinhedos" (para vinho).

Para franquear o diálogo e estabelecer transparência entre o governo brasileiro e os segmentos privados, foi realizada uma consulta pública no final de 2017, oportunidade em que se concedeu um prazo e se abriu um canal de comunicação para que os produtores brasileiros ou qualquer pessoa jurídica pudessem se manifestar ao (INPI) em oposição à lista de IGs apresentada.

As manifestações de oposição deveriam versar sobre os seguintes pontos:

a) Se a concessão de proteção de alguma IG fere direito adquirido.

b)Se nome idêntico ou similar, de forma a gerar confusão ao consumidor.

c) Se nome considerado genérico ou de uso comum.

d)Se o nome conflita com uma variedade vegetal ou raça animal, de forma a gerar confusão entre os consumidores

O ideal de uma perspectiva estratégia passa por uma dilatação da gestão de propriedade intelectual. Isso significa que, além da possibilidade de proteção de um produto, agregado a fatores territoriais, humanos e culturais, por meio de IG, talvez seja possível e exitosa a alternativa de proteção por outros institutos, como a marca coletiva.

Uma reflexão útil nesse processo de análise do contexto da realidade das IGs é a relação do Brasil e da UE com suas respectivas territorialidades.

A IG é um instituto por natureza conectado com os aspectos territoriais e geográficos. Portanto, quanto maior for a conexão entre o país e sua respectiva territorialidade, é bem provável que maior será a interconexão com as IGs. Por outro lado, quando o aspecto governamental é preponderante ao aspecto territorial, pode-se observar uma mitigação do potencial de crescimento das IGs.

Um exemplo positivo vem da UE, cuja constituição em bloco é extremamente institucionalizada e apoiada em aspectos territoriais, de maneira que a correlação com o reconhecimento 
das IGs foi algo natural e fluido, agregando valor às características administrativas, culturais e jurídicas da região.

No ano de 2017, a Organização das Nações Unidas para a Educação, a Ciência e a Cultura (UNESCO), por meio da instituição Fialho Salles Advogados, elaborou o projeto Análise dos interesses do Brasil e do Mercosul nas negociações do Acordo Comercial Mercosul-União Europeia, em benefício do Ministério da Indústria, Comércio Exterior e Serviços (MDIC), Secretaria de Inovação e Novos Negócios. Trata-se de um documento que circulou entre os órgãos do Poder Executivo Federal e teve por escopo identificar os interesses do Brasil, as margens negociadoras, as eventuais dificuldades enfrentadas, os aspectos defensivos e ofensivos da proposta do Acordo da EU-MERCOSUL, sob a perspectiva dos setores agrícola, de bebidas e alimentício. Também foram realizadas inúmeras entrevistas e franqueada às entidades representativas de segmentos econômicos a possibilidade de se manifestarem sobre os termos do Acordo.

Entre os países que compõem o MERCOSUL, em muitos momentos, são identificadas divergências e isso também se constitui objeto de preocupação de algumas entidades representativas, como é o caso da Associação Brasileira das Indústrias de Queijo (ABIQ), que destacou a diferença de práticas quanto à rotulagem de queijos que podem resultar em desvantagem aos produtos brasileiros ${ }^{3}$.

Um aspecto realçado por várias entidades é a necessidade de se preservar os direitos de titulares de registros ou usuários anteriores de marcas, por isso incluiu-se no Acordo uma cláusula que prevê a regra de convivência simultânea entre marcas previamente registradas e IGs protegidas. ${ }^{4}$ Atualmente, são objeto de proteção as IGs "Paraty" (n. IG200602), "Região de Salinas" (n. IG 200908) e "Microrregião da Abaíra" (n. BR02012000001-2).

Há produtos no mercado do Brasil que seguem a denominação "tipo"5 como: Brie, Camembert, Emental (Emmental), Gorgonzola, Gruyére, Gouda, Parmesão (Parmigiano), Provolone, Reino (Edam), Mozzarela de Búfala. Para a UE, pode-se mencionar o Cognac ${ }^{6}$, indicação francesa que já foi objeto de registro no Brasil, bem como o Scoth Whisky ${ }^{7}$, objeto de pedido de proteção como IG no Brasil.

Considera-se que o bloco europeu tenha adotado postura extremamente ofensiva na proposta feita ao MERCOSUL. Enquanto nos demais acordos a lista final de IGs da União Europeia a serem protegidas contém cerca de 170 designações, a proposta apresentada ao Mercosul em 2017 engloba mais de 340 nomes. A postura ofensiva fica ainda mais clara quando observadas as listas sob o recorte dos tipos de produtos abrangidos, por exemplo, com mais de 140 IGs de vinhos, quando os demais acordos abrangem, em média, cerca de 80, excetuando-se o Canadá. Observa-se também que mais de 30 IGs de vinhos que estão na proposta ao Mercosul não constam em algum dos demais acordos selecionados. ${ }^{8}$

No entanto, as expectativas eram de que o acordo envolvendo MERCOSUL e UE fosse celebrado no meio do ano de 2018, depois das tentativas de se compor algumas diferenças.

\footnotetext{
${ }^{3}$ Divergência entre o texto da Resolução n. 48/97 do GMC - MERCOSUL - Regulação Técnico Mercosul de Identidade e Qualidade do Queijo Azul (2.3: "Designação/Denominação de Venda: Será denominado "Queijo Azul”. E o texto da Instrução Normativa no $45 / 2007$ do MAPA (2.3 "Será denominado "Queijo Azul"”).

${ }^{4}$ Referida cláusula replica o previsto no artigo 14 do Regulamento n. 510/2006, do Conselho da UE.

${ }^{5}$ Conforme exigência contida na regulamentação técnica do MERCOSUL sobre rotulagem de alimentos embalados (artigo 3.3 do Regulamento anexo à RDC n. 259/2002).

${ }^{6}$ Registro n. IG980001, sob a titularidade de Bureau National Interprofessionel du Cognac.

7 Pedido n. BR412012000007-8, depositado por The Scoth Whisky Association, em 30/08/2012

${ }^{8}$ Essas informações foram obtidas por meio da participação dos autores deste artigo em negociações internacionais e da apresentação do documento Análise dos interesses do Brasil e do MERCOSUL nas negociações do Acordo Comercial MERCOSUL - União Europeia.
} 
O mês de abril desse ano foi repleto de agendas e conversas em Bruxelas (RITTNER, 2018), buscando-se solução factíveis, de maneira a pacificar os deals breakers, considerados como aspectos estratégicos.

\section{Considerações Finais}

São muitas as justificativas empregadas para o não reconhecimento, registro e proteção de IGs no Brasil, como o País ter dimensão territorial continental; ter um sistema público e dos órgãos administrativos incumbidos de viabilizar o reconhecimento e o registro das IGs burocrático; faltar conhecimento e informações mínimas sobre o instituto da IG, o que dificulta a conscientização das comunidades e associações para viabilizar o reconhecimento dos seus produtos; faltar cultura estratégica de gestão e proteção da propriedade intelectual, de todos os ativos intelectuais envolvidos na criação, especialmente quanto às IGs; faltar dados de articulação com os segmentos privados envolvidos e com os subsequentes impactos econômicos.

O reconhecimento, o registro e a proteção das IGs constituem um processo longo que demanda uma série de etapas, inúmeras articulações e interfaces humanas, além de diferentes níveis de diálogos (nacionais e internacionais).

Neste estudo, foi observada uma série de entraves e aspectos negativos que podem ser responsabilizados pelo avanço inexpressivo do reconhecimento das IGs no Brasil, considerando-se seu imenso potencial e sua convergência de culturas, por se tratar de um País formado historicamente de imigrantes (RITTNER, 2018).

O projeto Análise dos interesses do Brasil e do Mercosul, nas negociações do Acordo Comercial UE-MERCOSUL, identificou uma série de dificuldades na proteção e gestão de direitos de propriedade intelectual

[...] em função da demora na conclusão de procedimentos (backlog) no INPI, obstáculos resultantes das normas sobre transferência de tecnologia (tais como a necessidade de registro) dos contratos junto ao INPI para remessas ao exterior, alta carga tributária na importação de serviços e tecnologias, limitações impostas pela Lei de Inovação, escassez de políticas de fomento à inovação, baixo grau de especialização e capacitação do Judiciário para decisões sobre propriedade intelectual, entre outras.

Já sob a perspectiva da UE, foram identificados obstáculos relacionados às barreiras técnicas ou sanitárias (exigências afetas ao $\mathrm{REACH}$ ) e, na área de propriedade intelectual, foram mencionados os custos elevados e variáveis para se obter uma patente em cada um dos países do bloco europeu.

Há entidades representativas de segmentos do mercado brasileiro que refutam a extenção de proteção a uma série de produtos, sob o argumento de que o Brasil é um País de imigrantes e que referidos produtos não seriam privilégio exclusivo de determinadas regiões (RITTNER, 2018).

A Associação Brasileira de Proteína Animal (ABPA) manifestou sua preocupação especificamente quanto à manutenção do direito de uso das seguintes expressões: Jamón, Coppa, Presunto Parma, Salame Hamburguês, Salame Italiano, Salame Milano, Linguiça Calabresa, Linguiça Portugesa, Linguiça Toscana, Mortadela Bologna, entre outros. 
A Associação Brasileira dos Produtores e Exportadores de Cachaça (ABPEC) destacou que os principais obstáculos à exportação da cachaça para o bloco europeu são as exigências e os padrões técnicos estabelecidos. Todos os setores que representam esse segmento manifetaram preocupação com a preservação e proteção do termo "cachaça", conforme determinado no Decreto n. 4.062, de 21 de dezembro de 2001. Para conferir segurança à proteção da tequila e do mezcal, o México adotou procedimentos quando celebrou o seu acordo com a UE, em 1997. 9

O Instituto Brasileiro do Vinho (IBRAVIN) mencionou que, apesar de estar registrado o uso da IG Champagne, há uma decisão judicial que autoriza a utilização do uso desse termo. ${ }^{10}$ O Instituto também defendeu a necessidade de se preservar o uso corrente e estratégico para o setor, sob a denominação de "menções tradicionais", na legislação europeia. ${ }^{11}$

A Confederação Nacional da Agricultura e Pecuária (CNA) informou que o setor de lácteos tem muitas preocupações, especificamente com a referência aos tipos e à preservação de seus usos, como é o caso dos queijos parmesão e gruyére produzidos no Brasil.

As observações da Confederação Nacional da Indústria (CNI) concentram-se principalmente na viabilidade de cláusulas de cooperação entre os países e na receptividade de dispostições sobre enforcement bem elaboradas.

Especificamente no que se refere às negociações internacionais, serão apontados, a seguir, aspectos que comprometem o êxito das tratativas.

\section{Ausência de dados}

Em que pese o imenso potencial do Brasil, o que se observa é uma ausência de dados suficientemente levantados e consolidados, de maneira a conferir segurança jurídica e clareza no encaminhamento das negociações, pois são frequentes as manifestações sobre determinados assuntos quase "no escuro", em razão da identificação de dados mínimos sobre o tema.

\section{Ausência de profissionalização em negociação}

Negociação profissional demanda técnica, capacitação e preparo. Dessa forma, é necessário preparar os agentes representantes da negociação com o máximo de expertise e sutilezas possíveis. Ao utilizar como exemplo o bloco europeu, é evidente o nível de treinamento de seus negociadores e das técnicas, que fazem total diferença nos trâmites.

\section{Ausência de cultura de negociação}

A consolidação recente da ciência relacionada à propriedade intelectual impacta, necessariamente, a ausência de cultura de negociação, ou seja, não há uma tradição, um nivelamento técnico e de informação.

\footnotetext{
${ }^{9} \mathrm{Na}$ atualização do Acordo, em 2004, o México inclui os termos "sotol" e "charanda".

${ }^{10}$ Recurso Extraordinário n. 78.835, julgado pelo Supremo Tribunal Federal, em 1974.

${ }^{11}$ Artigo 29 do Regulamento (CE) n. 607/2009 da Comissão Europeia.
} 
O que ocorre é até mesmo o contrário, uma vez que os poucos agentes que se apropriam do tema com frequência se movimentam em outras funções profissionais, e essa falta de retenção de profissionais capacitados compromete o histórico, a memória e o avanço das negociações.

\section{Burocracia}

A burocracia ${ }^{12}$ sempre é um entrave, tanto nos trâmites administrativos de reconhecimento e registro das indicações geográficas quanto no momento da negociação internacional, porque afeta o ritmo e a fluidez do diálogo. Nesse sentido, nota-se um avaço na simplificação dos normativos referentes ao processo de proteção das IGs. ${ }^{13}$

\section{Necessidade de composição política}

A composição política é um desafio recorrente, quando se analisa negociações internacionais relacionadas a IGs. No Brasil, o tema é tratado por vários Ministérios, como o da Agricultura; do Desenvolvimento, Indústria e Comércio Exterior; e do Planejamento; pelo INPI, entre outros. Portanto, a composição de interesses políticos, nem sempre lineares e convergentes, não é tarefa fácil, especialmente considerando-se momentos de instabilidade política.

\section{Impactos econômicos das negociações por segmento}

Aspecto fundamental e extremamente sensível para o avanço das negociações internacionais é o estudo fidedigno dos impactos econômicos das negociações por segmento.

A complexidade e a riqueza do debate sobre o tema IGs estão em uma análise não simplificada ou linear. Significa dizer que, para cada segmento, há uma reflexão específica, sob considerações e peculiaridades únicas. Assim, a depender da abordagem que se está conferindo à IG, há um impacto mais sensível para o segmento de lácteos do que para o segmento de carnes, de vinhos, entre tantos outros.

\section{Articulação com os segmentos privados}

Em razão das especificidades de cada segmento, conforme mencionado anteriormente, a articulação com a iniciativa privada correspondente ao mercado que irá ser analisado é fundamental. Primeiro, porque o diálogo fica mais pacificado, na medida em que não há o fator surpresa e há a interface das informações. Segundo, porque há o compartilhamento de dados específicos e o conhecimento do impacto econômico das negociações naquele segmento, conforme já mencionado.

Uma negociação não é composta somente das partes diretamente envolvidas em seu processo. Em verdade, há uma série de agentes externos que influenciam e condicionam as

\footnotetext{
12 "[...] observa-se que, de 112 pedidos de registro apresentados ao INPI desde 1997, apenas 62 foram concedidos.” Análise dos interesses do Brasil e do Mercosul nas negociações do Acordo Comercial Mercosul - União Europeia.

${ }^{13}$ Instrução Normativa n. 70/2017 e Resolução n. 199/2017 do INPI.
} 
rodadas de negociação, que podem ser tanto da iniciativa privada, segmentos econômicos dos mais diversos, como da academia ou de outros setores do governo.

\section{Racionalidade das rodadas de negociação internacionais}

As rodadas de negociação são encontros profissionais, com interesses (ainda que não explícitos) muito claros, razão pela qual a racionalidade deve imperar, agregando-se a isso fatores de observação, controle emocional e exatidão.

A negociação pode ser comparada a um jogo de xadrez, cuja dinâmica é estabelecida passo a passo e, até certo ponto, sob elementos previsíveis. Dessa forma, as partes negociadoras devem estar adstritas a um estado de atenção e presença absoluto, pois os fatos nem sempre são alcançáveis por meio de uma explicação, contendo-se elementos muito sutis e implícitos.

O fator emocional tende a atrapalhar os trâmites, porque deixa explícito o desiderato da parte envolvida, o que nem sempre é estratégico. Além do mais, a emoção pode ser facilmente utilizada como um elemento contra a parte que a sente, porque é muito fácil levá-la ao limite $e$, por conseguinte, forçá-la a anuir com termos que não seriam do seu agrado.

O Brasil tem um potencial de produção de IG ainda não explorado que aponta para um fator de fraqueza nas negociações internacionais não somente pelo pequeno número atual de suas IGs, mas pela maneira como a negociação é realizada. Falta apoio maior e uma vontade de concluir a negociação no Brasil e no MERCOSUL, este à frente das demandas internacionais.

Diante do exposto, depreende-se que, para fins de avanço nas negociações internacionais afetas às IGs, faz-se necessário imprimir uma estratégia eficaz, que perpasse por todos os aspectos discriminados neste artigo. Caso contrário, sempre haverá uma posição defensiva dos setores e segmentos representados, que não necessariamente traduzem um posicionamento racional, estratégico e profícuo para o Brasil.

Por outro lado, na realização de um esforço interno, apontam-se os seguintes problemas: ausência de dados; ausência de profissionalização em negociação e em instituições; ausência de cultura de negociação; excesso de burocracia; necessidade de composição política nacional e local; necessidade de estudos de impactos econômicos das negociações por segmento; necessidade de articulação com os segmentos privados.

No processo de constituição de uma IG, reitera-se, não há somente as partes diretamente envolvidas na negociação. Em verdade, há uma série de agentes externos que influenciam e condicionam as rodadas de negociação, os quais podem ser tanto da iniciativa privada, segmentos econômicos dos mais diversos, como da academia ou de outros setores do governo. Sendo a IG uma proteção local, é fundamental que a articulação das negociações ocorra nos vários níveis políticos (nacional, estadual e local), implantando-se uma política de desenvolvimento regional.

\section{Referências}

ALMEIDA, A. F. R. de. Denominação de origem e marca. Coimbra: Coimbra Ed., 1999.

AMORIM, J. A.; MISKULIN, M. S. Multimídia engineering: methodological contributions to digital content production and use in education. In: SIMPÓSIO BRASILEIRO DE INFORMÁTICA NA EDUCAÇÃO (SBIE), 21., João Pessoa, PB, 2010. Anais... João Pessoa, JB: CDT-IE, 2010. 
BOFF, S. O. et al. Propriedade intelectual: marcos regulatórios. Erechim: Editora Deviant, 2017. Livro digital.

BRASIL. Câmara dos Deputados. Projeto de Lei n. 5.402, de 18 de abril de 2013. Autoria: Newton Lima - PT/SP e Dr. Rosinha - PT/PR. [2013a]. Disponível em: <http://www.camara.gov.br/ proposicoesWeb/fichadetramitacao?idProposicao $=572965>$. Acesso em: 5 maio 2018 .

Decreto n. 16.254, 19 de dezembro de 1923. Cria a Diretoria Geral da Propriedade Industrial. [1923]. Disponível em: <http://denisbarbosa.addr.com/lei16254.htm>. Acesso em: 22 maio 2018.

Decreto n. 2.366, 5 de novembro de 1997. Regulamenta a Lei n. 9.456, de 25 de abril de 1997, que institui a Proteção de Cultivares, dispõe sobre o Serviço Nacional de Proteção de Cultivares (SNPC0, e dá outras providências. [1997a]. Disponível em: <http://www.planalto.gov.br/ ccivil_03/decreto/1997/d2366.htm>. Acesso em: 8 maio 2018.

Decreto-Lei n. 254, de 28 de fevereiro de 1965. Código de Propriedade Industrial. [1965]. Disponível em: <http://www.planalto.gov.br/ccivil_03/decreto-lei/1965-1988/Del0254.htm> . Acesso em: 22 maio 2018.

Decreto-Lei n. 7.903, de 27 de agosto de 1945. Código de Propriedade Industrial. [1945]. Disponível em: <http://www.planalto.gov.br/ccivil_03/decreto-lei/1937-1946/Del7903.htm>. Acesso em: 22 maio 2018.

Instituto Nacional da Propriedade Industrial (INPI). Instrução Normativa n. 25, de 21 de agosto de 2013. [2013b]. Estabelece as condições para o Registro das Indicações Geográficas. Disponível em: <http://www.inpi.gov.br/legislacao-1/in_25_21_de_agosto_de_2013.pdf >. Acesso em: 8 maio 2018.

Lei Complementar n. 105, de 10 de janeiro de 2001. Dispõe sobre o sigilo das operações de instituições financeiras e dá outras providências. [2001]. Disponível em: <http://www. planalto.gov.br/ccivil_03/leis/LCP/Lcp105.htm > . Acesso em: 8 maio 2018.

Lei n. 12.965, de 23 de abril de 2014. Marco Civil da Internet. Estabelece princípios, garantias, direitos e deveres para o uso da Internet no Brasil. [2014]. Disponível em: <http://www. planalto.gov.br/ccivil_03/_ato2011-2014/2014/lei/112965.htm>. Acesso em: 5 maio 2018.

Lei n. 9.279, de 14 de maio de 1996. Regula direitos e obrigações relativos à Propriedade Industrial, inclusive indicações geográficas. [1996]. Disponível em: <http://www. planalto.gov.br/ccivil_03/leis/L9279.htm>. Acesso em: 5 maio 2018.

Lei n. 9.456, de 25 de abril de 1997. Institui a Lei de Proteção de Cultivares e dá outras providências. [1997b]. Disponível em: <http://www.planalto.gov.br/ccivil_03/leis/L9456.htm>. Acesso em: 9 maio 2018.

Lei n. 9.609, de 19 de fevereiro de 1998. Dispõe sobre a proteção da propriedade intelectual de programa de computador, sua comercialização no País, e dá outras providências. [1998a]. Disponível em: <http://www.planalto.gov.br/ccivil_03/leis/L9609.htm>. Acesso em: 5 maio 2018.

Lei n. 9.610, de 19 de dezembro de 1998. Altera, atualiza e consolida a legislação sobre direitos autorais e dá outras providências. [1998b]. Disponível em: <http://www.planalto.gov.br/ ccivil_03/leis/L9610.htm>. Acesso em: 10 maio 2018.

Lei n. 5.772, de 21 de dezembro de 1971. Código de Propriedade Industrial. [1971]. Disponível em: <http://www.planalto.gov.br/ccivil_03/Leis/L5772.htm>. Acesso em: 23 maio 2018. 
Ministério da Indústria, Comércio Exterior e Serviços. Brasil avalia reconhecimento de Indicações Geográficas da União Europeia. 2017. Disponível em: < http://www.mdic.gov. br/index.php/noticias/2903-brasil-avalia-reconhecimento-de-indicacoes-geograficas-da-uniaoeuropeia >. Acesso em: $28 \mathrm{dez} .2018$.

Supremo Tribunal Federal. Ação Direta de Inconstitucionalidade n. 5061/ DF. Relator(a): Min. Luiz Fux. [2018]. Disponível em: <http://www.stf.jus.br/portal/processo/ verProcessoAndamento.asp?incidente $=4490434>$. Acesso em: 14 maio 2018.

CHADE. J. Governo já não acredita em acordo comercial com Europa. 2018. Disponível em: $<$ https://economia.estadao.com.br/noticias/geral,governo-ja-nao-acredita-em-acordo-comercial-comeuropa,70002162718?from = whatsa $>$. Acesso em: 28 dez. 2018.

Cosbey, A. The Sustainable Development Effects of the WTO TRIPS Agreement: a focus on developing countries, international institute for sustainable development. 1996. Disponível em: $<$ https://www.iatp.org/sites/default/files/Sustainable_Development_Effects_of_the_WTO_TRI.htm > . Acesso em: 5 maio 2018.

Croze, D. Protection of Well-Known Marks. Journal of Intellectual Property Rights, [S.l.], v. 5, p. 137-151, maio 2000. Disponível em: <http://nopr.niscair.res.in/bitstream/123456789/19496/1/ JIPR\%205(3)\%20137-151.pdf>. Acesso em: 5 maio 2018.

DESIGN ON TRADE AGREEMENT (DESTA). Base de dados on-line. [2018]. Disponível em: $<$ http://www.designoftradeagreements.org/www.designoftradeagreements.org/index.html >. Acesso em: 5 maio 2018.

EUROPEAN UNION INTELLECTUAL PROPERTY OFFICE (EUIPO). Base de dados on-line. [2018]. Disponível em: < https://euipo.europa.eu/ohimportal/pt/databases > . Acesso em: 5 maio 2018.

FRAMEWORK CONVENTION ON CLIMATE CHANGE (FCCC). Part Two: Action taken by the Conference of the Parties at its sixteenth session. In: CONFERENCE OF THE PARTIES, 16., Cancun, 2010. Report... Cancun: United Nations, 2011. Disponível em: <https://unfccc.int/resource/ docs/2010/cop16/eng/07a01.pdf > . Acesso em: 11 maio 2018.

Technology Mechanism. [2018]. Disponível em: <http://unfccc.int/ttclear/support/ technology-mechanism.html >. Acesso em: 8 maio 2018.

INSTITUTO MINEIRO DE AGROPECUÁRIA (IMA). Governo de Minas libera recursos para a pesquisa na área de queijos artesanais. 2018. Disponível em: <http:/www.ima.mg.gov.br/ acontece-no-ima/2321-governo-de-minas-libera-recursos-para-a-pesquisa-na-area-de-queijosartesanais >. Acesso em: 20 maio 2018.

INTERNATIONAL CONVENTION FOR THE PROTECTION OF NEW VARIETIES OF PLANTS, 1978, Geneva. Anais eletrônicos... Geneva: [s.n.], 1978. Disponível em: <http://www.upov.int/ upovlex/en/conventions/1978/content.html> . Acesso em: 11 maio 2018.

, 1991, Geneva. Anais eletrônicos... Geneva: [s.n.], 1991. Disponível em: <http://www. upov.int/upovlex/en/conventions/1991/content.html > . Acesso em: 11 maio 2018.

LE FIGARO. De grands chefs se mobilisent pour sauver «le vrai camembert». 2018. Disponível em: <http://www.lefigaro.fr/conso/2018/05/15/20010-20180515ARTFIG00290-de-grands-chefs-semobilisent-pour-sauver-le-vrai-camembert.php> . Acesso em: 28 dez. 2018. 
MARCONI, M. A; LAKATOS, E. M. Fundamentos da metodologia científica. 6. ed. São Paulo: Atlas, 2005. 315 p.

MOREIRA, A. Da UE para a China. 2018. Disponível em: < https://www.valor.com.br/ agro/5290497/da-ue-para-china >. Acesso em: 28 dez. 2018.

ORGANIZAÇÃO PARA A COOPERAÇÃO E DESENVOLVIMENTO ECONÔMICO. Manual de Oslo: diretrizes para coleta e interpretação de dados sobre inovação. 3. ed. Rio de Janeiro: OECD/ EUROSTAT/FINEP, 1997.

PEROVANO, D. G. Manual de metodologia científica para a segurança pública e defesa social. Curitiba: Juruá, 2014.

Practical Law (PLC). IP in Business Transactions Global Guides. [2018]. Disponível em: <https:/uk.practicallaw.thomsonreuters.com/Browse/Home/International/

IPinBusinessTransactionsGlobalGuide?_lrTS=20170507154117446\&transitionType=Default\&cont extData $=$ (sc.Defa $>$. Acesso em: 10 maio 2018.

RITTNER, D. A cerveja que complica o acordo UE-Mercosul. 2018. Disponível em: <http:// barreirasdeacesso.com.br/BarrierRules/LoadNewsId/54>. Acesso em: 15 abr. 2018.

SISTEMA DE INFORMAÇÃO DE COMÉRCIO EXTERIOR (SICE). Portal institucional on-line. [2018]. Disponível em: <http://www.sice.oas.org/> . Acesso em: 14 ago. 2018.

STONE, J. Britain wants the EU to protect its products from imitation post-Brexit, but is reluctant to return the favour. 2018. Disponível em: <https://www.independent.co.uk/news/uk/ politics/uk-regional-specialities-eu-protect-trade-deal-europe-cheese-food-drink-wine-a8312171. html>. Acesso em: $28 \mathrm{dez} .2018$.

U.S. DAIRY criticizes GI provision in E.U.- Mexico agreement as E.U. farmers praise. 2018.

Disponível em: <https:/www.tsln.com/news/us-dairy-criticizes-gi-provision-in-eu-mexico-agreementwhile-eu-farmers-praise-it/>. Acesso em: 28 dez. 2018.

UNIÃO EUROPEIA (UE). Commission notice n. 2016/C 244/03 on the customs enforcement of Intellectual Property Rights concerning goods brought into the customs territory of the Union without being released for free circulation including goods in transit. [2016]. Disponível em: <http://eur-lex.europa.eu/legalcontent/EN/TXT/?uri=uriserv:OJ .C_.2016.244.01.0004.01.ENG\&toc=OJ:C:2016:244:FULL>. Acesso em: 14 maio 2018.

Commission notice n. C/2016/4032 on the customs enforcement of Intellectual Property Rights concerning goods brought into the customs territory of the Union without being released for free circulation including goods in transit. [2016]. Disponível em: <http:// eur-lex.europa.eu/legal-content/EN/ALL/?uri=CELEX:52016XC0705(02)>. Acesso em: 14 maio 2018.

Commission Regulation (EC) n. 772/2004 on the application of Article 81(3) of the Treaty to categories of technology transfer agreements. [2004]. Disponível em: <http://eur-lex. europa.eu/legal-content/EN/TXT/HTML/?uri=CELEX:32004R0772\&from=EN>. Acesso em: 14 maio 2018.

Council Regulation (EC) n. 6/2002 de 12 Dezembro de 2001 relativa aos desenhos industriais on Community designs (estabelece o sistema de obtenção de registro de desenhos industriais desenho da União Europeia, perante a EUIPO). [2002]. Disponível em: <http://eur-lex.europa.eu/legal-content/EN/TXT/?uri=celex:32002R0006> . Acesso em: 14 maio 2018. 
Directive 2001/29/EC of the European Parliament and of the Council of 22 May 2001 on the harmonisation of certain aspects of copyright and related rights in the information society. [2001]. Disponivel em: <http://eur-lex.europa.eu/LexUriServ/LexUriServ.do?u ri $=$ CELEX:32001L0029:EN:HTML> . Acesso em: 14 maio 2018.

Directive 2004/48/EC of the European Parliament and of the Council of 29 April 2004 on the enforcement of intellectual property rights. [2004]. Disponível em: <http://eurlex.europa.eu/LexUriServ/LexUriServ.do?uri=OJ:L:2004:195:0016:0025:en:PDF> . Acesso em: 14 maio 2018.

. Directive 2006/116/EC of the European Parliament and of the Council of 12 December 2006 on the term of protection of copyright and certain related rights. [2006]. Disponível em: < http://eur-lex.europa.eu/legal-content/EN/ALL/?uri=CELEX\%3A32006L0116> . Acesso em: 11 maio 2018.

Directive 98/71/EC of the European Parliament and of the Council of 13 October 1998 on the legal protection of designs. [1998]. Disponível em: <http://eur-lex.europa.eu/legalcontent/EN/ALL/?uri=CELEX\%3A31998L0071 > . Acesso em: 14 maio 2018.

Guidelines of the European Commission concerning the enforcement by EU customs authorities of intellectual property rights with regard to goods, in particular medicines, in transit through the EU. Confidencial Projeto UNESCO - Relatório 2, junho de 2017.

Regulation (EU) No 608/2013 of the European Parliament and of the Council of 12 June 2013 concerning customs enforcement of intellectual property rights and repealing Council Regulation (EC) No 1383/2003. [2013]. Disponível em: <http://eur-lex.europa.eu/ LexUriServ/LexUriServ.do?uri=OJ:L:2013:181:0015:0034:en:PDF>. Acesso em: 14 maio 2018.

Regulation (EU) no. 1151/2012 of the European Parliament and of the Council of 21 November 2012 on quality schemes for agricultural products and foodstuffs. [2012]. Disponível em: http://eur-lex.europa.eu/LexUriServ/LexUriServ.do?uri=OJ:L:2012:343:0001:0029:e n:PDF. Acesso em 14 de maio de 2018.

UNIVERSIDADE FEDERAL DE LAVRA (UFLA). Núcleo de Inovação Tecnológica da UFLA. Indicação Geográfica. Disponível em: <http://www.nintec.ufla.br/propriedade-intelectual/ indicacao-geografica $>$. Acesso em: 8 maio 2018.

VALERO, J. Mexico wins 'cheese war' over Europe in trade deal. 2018. Disponível em: < https:// www.euractiv.com/section/economy-jobs/news/mexico-wins-cheese-war-over-europe-in-trade-deal/> . Acesso em: 28 dez. 2018.

VOITCH, T. B. Projeto de Lei para Regulamentar produção de queijos no Paraná. 2018.

Disponível em: < http://www.gazetadopovo.com.br/bomgourmet/lei-producao-queijos-artesanaisparana/>. Acesso em: 20 maio 2018.

WORLD HEALTH ORGANIZATION. Global strategy plan of action on public health, innovation and intellectual property. 2011. Disponível em: <http://www.who.int/phi/publications/ Global_Strategy_Plan_Action.pdf $>$. Acesso em: 12 maio 2018.

Sixty-second World Health Assembly. WHA resolution 62.16. Global strategy and plan of action on public health, innovation and intellectual property. 2009. Disponível em: <http://apps.who. int/gb/ebwha/pdf_files/A62/A62_R16-en.pdf>. Acesso em: 12 maio 2018.

WORLD INTELLECTUAL PROPERTY ORGANIZATION. Development agenda for WIPO. [2018]. Disponível em: <http://www.wipo.int/ip-development/en/agenda>. Acesso em: 12 maio 2018. 
International Classification of Goods and Services. 10. ed. Geneva: WIPO Publication, 2011. Disponível em: <http:/www.wipo.int/classifications/nivilo/pdf/eng/nice/10engp2.pdf > . Acesso em: 8 maio 2018.

Joint Recommendation Concerning Provisions on the Protection of Well-Known Marks. 2000. Disponível em: <http://www.wipo.int/edocs/pubdocs/en/marks/833/pub833.pdf>. Acesso em: 12 maio 2018.

Standing Commitee on the Law of Patents. Feasibility study on the disclosure of international nonproprietary names (inn) in patent applications and/or patents. 2014. Disponível em: <http://www.wipo.int/edocs/mdocs/scp/en/scp_21/scp_21_9.pdf>. Acesso em: 12 maio 2018.

Standing Commitee on the Law of Patents. Report. 2014. Disponível em: < http://www. wipo.int/edocs/mdocs/scp/en/scp_21/scp_21_12.pdf>. Acesso em: 12 maio 2018.

Summary Table of Membership of the World Intellectual Property Organization (WIPO) and the Treaties Administered by WIPO, plus UPOV, WTO and UN. [2018]. Disponível em: <http://www.wipo.int/treaties/en/summary.jsp>. Acesso em: 12 maio 2018.

WIPO-Administered Treaties. [2018]. Disponível em: <http:/www.wipo.int/treaties/en>. Acesso em: 12 maio 2018.

WORLD TRADE ORGANIZATION. Trade-Related Aspects of Intellectual Property Rights. [2018]. Disponível em: <https://www.wto.org/english/tratop_e/trips_e/trips_e.htm>. Acesso em: 12 maio 2018.

\title{
Sobre os Autores
}

\begin{abstract}
Alessandro Aveni
E-mail: alessandro@unb.br

Formação: Doutor em Ciências Políticas, pela Universidade de Milan, e em Administração, pela Universidade Cormercial Luigi Bocconi, ambas na Itália; mestre em Geografia, pela Universidade de Brasília (UnB); especialista em Estratégia Empresarial, pela Fundação Getúlio Vargas (FGV); e bacharel em Administração, pela UnB.

Endereço profissional: Centro de Apoio ao Desenvolvimento Tecnológico (CDT), Universidade de Brasília. Campus Universitário Darcy Ribeiro, s/n., - Brasília, DF. CEP: 70910-900.
\end{abstract}

\section{Carolina Leite Diniz Panzolini}

E-mail: carolina.panzolini@cultura.gov.br

Formação: Mestra em Propriedade Intelectual, pela Universidade de Brasília (UnB); especialista em Propriedade Intelectual, pela Organização Mundial de Propriedade Intelectual - Universidade George Mason (EUA) $e$ Universidade de Londres (Kings College) -, e em regulação, pela Universidade Georgetown (EUA).

Endereço profissional: Ministério da Cultura, Esplanada dos Ministérios, Bloco B, $2^{\circ}$ andar - Brasília, DF. CEP: 70068-900.

\section{Daniela Soares Couto Saldanha}

E-mail: danielacouto.adv@gmail.com

Formação: Mestranda em Propriedade Intelectual, Transferência de Tecnologia para Inovação, pela Universidade de Brasília (UnB); especialista em Direito Processual Civil, pela Universidade do Sul de Santa Catarina (Unisul); e bacharela em Direito, pela Universidade Salgado de Oliveira (Universo).

Endereço profissional: Rua 10, n. 93, sala 6, Setor Oeste - Goiânia, GO. CEP 74120-020. 


\section{Jéssica Pinto Lima}

E-mail: jessica.lima@cultura.gov.br

Formação: Mestranda em Propriedade Intelectual, Transferência de Tecnologia para Inovação, pela Universidade de Brasília (UnB); e bacharela em Direito, pela IESPLAN.

Endereço profissional: Ministério da Cultura, Esplanada dos Ministérios, Bloco B, $2^{\circ}$ andar - Brasília, DF. CEP: 70068-900. 